\title{
Jogos angolanos como ferramenta pedagógica para o ensino de matemática: um estudo na perspectiva do Programa Etnomatemática
}

\author{
Angolan games as a pedagogic tool for teaching mathematics: a study \\ from the perspective of the Ethnomathematics Program
}

\author{
Cristiane Coppe \\ Universidade Federal de Uberlândia \\ criscopp@ufu.br \\ ORCID $0000-0002-0378-810 \mathrm{X}$
}

\author{
Domingos Mateus Mandavela Monteiro \\ Universidade Lueji A'Nkonde/Angola \\ dm312011@hotmail.com \\ ORCID: 0000-0001-6164-916X
}

\begin{abstract}
Resumo. Este artigo é um recorte da dissertação de mestrado do segundo autor, junto ao Programa de Mestrado em Ciências da Educação da Universidade Lueji A'Nkonde (Angola), desenvolvido em parceria com o Programa de Pós-Graduação em Educação da FEUSP. Tem como proposta apresentar dois jogos angolanos que podem contribuir, como ferramenta didática, no processo de ensino e de aprendizagem em matemática. De abordagem qualitativa, tendo como aporte teórico as dimensões do cotidiano e educacional do Programa Etnomatemática e teóricos que defendem os jogos e brincadeiras no ensino de matemática, aplicou-se um questionário aos futuros professores (profissionais que atuarão como o correspondente ao nosso Ensino Fundamental I) do $4^{\circ}$ ano de magistério da instituição. Os primeiros resultados levantados, a partir dos discursos dos sujeitos, apresentaram dois jogos angolanos, que, na concepção dos futuros professores que ensinarão matemática, podem e devem ser utilizados no ensino da matemática.
\end{abstract}

Palavras-chave. Jogos angolanos. Ensino de Matemática. Programa Etnomatemática.

Abstract. This article is an section of the master's thesis of the second author, together with the Master's Program in Educational Sciences of Lueji A'Nkonde University (Angola), developed in partnership with the Graduate Program in Education of FEUSP. Its proposal is to present two Angolan games that can contribute, as a didactic tool, to the teaching and learning process in mathematics. From a qualitative approach, having as theoretical contribution the dimensions of daily and educational of the Ethnomathematics Program and 
theorists who defend games and games in the teaching of mathematics, a questionnaire was applied to future teachers (professionals who will act as the corresponding to our Elementary School I) of the 4th year of teaching of the institution. From a qualitative approach, having as theoretical contribution the dimensions of daily and educational of the Ethnomathematics Program and theorists who defend the games and games in the teaching of mathematics. A questionnaire was applied to future teachers (professionals who will act as the corresponding to our Elementary School I) of the 4th year of teaching of the institution. The first results obtained, from the subjects' discourses, presented two Angolan games, which, in the conception of future teachers who will teach mathematics, can and should be used in the teaching of mathematics.

Keywords. Angolan games. Mathematics Teaching. Ethnomathematics Program.

Mathematics Subject Classification (MSC): primary 97B50.

\section{Introdução}

Na Década de 90, em Angola, e em particular na Província da Lunda-Norte, era possível perceber como os jovens daquela época se dedicavam em aprender diversos conteúdos. Mas, que tipo de aprendizagem pretendiam alcançar? Pretendia-se considerar a aprendizagem em termos de preservar (ressaltar os valores) que fazem parte da cultura e da identidade de um povo. Não havia naquela época a explosão da ciência e da tecnologia que hoje pode-se constatar, ou seja, a entrada do mundo tecnológico desencadeou descontinuidades em muitos aspectos culturais. $\mathrm{O}$ angolano que, em algumas horas do seu dia, jogava e brincava, criou um desinteresse com esses costumes, pois os jogos e as brincadeiras que antes faziam parte do cotidiano nos municípios, nas comunas (pequenas comunidades), nos bairros e nas aldeias, não ocorriam a partir da influência que a tecnologia foi impondo envolvendo os adultos e as crianças.

Os alunos, as crianças da atualidade em particular, desconhecem a maioria dos jogos e brincadeiras tradicionais da cultura angolana, pois as movimentações e deslocamentos que muitas famílias tiveram, ao sair de um lugar cultural para tecnológico, acelerou-se com o surgimento da internet, que de fato é um bom passo para frente, mas acabou desfalcando a vertente cultural dos estudantes.

Quando, por exemplo, se depara com um grupo de crianças do bairro, assim como de casa, tentando fazer alguns desenhos na areia, jogar a macaca, brincar de garrafinha e jogar de pedrinhas, percebe-se que o jogar/ brincar faz parte do processo cognitivo 
da criança, pois a capacidade que elas apresentam em realizar algumas ações revelam elementos criativos, logicamente coerentes que leva, por alguns minutos, a um passado cultural relevante para o contexto angolano.

No entanto, partindo do pressuposto de que algumas reformas educacionais estão sendo realizadas, no sentido de que o professor deixe de pensar que o aluno é um ser passivo, sem raízes culturais e sem capacidade de raciocínio, torna-se necessário que se perceba o quanto os estudantes têm potencial, criatividade e dinâmica para lidar com situações do cotidiano, apropriando-se da ludicidade nos jogos/brincadeiras e podendo ser um elemento didático que pode contribuir para o processo de ensino e de aprendizagem em matemática.

Nessa perspectiva, encontra-se a proposta do projeto de pesquisa de mestrado do segundo autor, em investigar jogos e brincadeiras angolanas no Ensino da Matemática, considerando o programa Etnomatemática, considerando o fato de que o ser humano, desde a Antiguidade, preocupou-se em buscar dentro da sua própria cultura, conhecimentos (matemáticos) para sua sobrevivência e transcendência, muitas vezes de forma lúdica.

A ludicidade é um elemento que sempre fez parte da vida cotidiana do ser humano e nesse sentido os jogos/brincadeiras protagonizaram elementos relevantes para as relações interpessoais, bem como a produção de conhecimentos.

A escolha do tema de pesquisa teve forte influência com o ingresso do segundo autor no mestrado em Ciências da Educação no ano 2018 na Universidade Lueji A'Nkonde em Lunda Norte/Angola e os primeiros módulos que foram ministrados, dentre eles o de Política, Organização da Educação e do Ensino em Angola, o Programa Etnomatemática e aliado a Conferência Internacional da Etnomatemática. Outro movimento que levou à escolha do tema foram as primeiras orientações da investigação e o fato do pesquisador, a partir da sua prática em uma escola do magistério primário em Chitato/Angola em considerar a diversidade de etnia entre seus estudantes, acreditar que a formação de professores que ensinam matemática pode ser pautada em competências, qualidade e tomada de decisão no que se refere a atender às necessidades tanto de seus alunos, quanto do currículo, a fim de propiciar possibilidades para a escolha de intervenções didático-pedagógicas que contribuam para o processo de ensino-aprendizagem em Matemática.

Diante do exposto, neste artigo serão apresentados os primeiros resultados da investigação, a partir do levantamento, por meio do instrumento qualitativo questionário, apenas de dois jogos que evidenciaram potencialidades pedagógicas para o ensino de matemática na concepção de futuros professores.

Neste artigo, serão evidenciados dois jogos levantados como possibilidades entre os sujeitos da pesquisa, a partir da aplicação de um questionário a futuros professores que ensinarão matemática. Desse modo, espera-se olhar para matemática voltada para a 
sua vertente sociocultural, buscando uma conexão com os conhecimentos que os futuros professores (profissionais) possuem acerca de jogos e suas ideias matemáticas. Para tanto, elegeu-se o Programa Etnomatemática como campo teórico que auxiliou na discussão/reflexão do primeiro movimento de análise dos dados, considerando, principalmente as dimensões: educacional e os desafios do cotidiano. Um outro elemento articulador para essa proposta foi a ludicidade, que é um valor cultural africano que deve ser ressaltado no processo de ensino e de aprendizagem da matemática.

\title{
2 Caminhos teóricos
}

Atividades como jogos / brincadeiras são pertinentes no universo da criança, pois estimulam a espacialidade, a localização no espaço. O jogo da macaca, brincadeira de garrafinha e jogo de pedrinha são atividades que, se forem bem aproveitadas na sala de aula, explorariam melhor o potencial que as crianças possuem, pois Orey \& Rosa (2004), citados por De Oliveira [9] (2006), afirmam que as crianças, ao redor do mundo, "têm se divertido muito, desenhando os traçados de amarelinha nas calçadas, nas ruas, nos pátios dos recreios escolares, ou nos quintais e jardins de casa, mas também dizer que sem elas dar-se em conta aprendem muito com os jogos/brincadeiras." (DE OLIVEIRA [9], 2006, p. 91).

Os jogos e brincadeiras devem ser colocados no sentido de estimular, motivar e cativar as crianças para que elas se sintam mais desafiadas e busquem soluções para alguns problemas matemáticos. Zaslavsky [15] (2009) traz que,

\begin{abstract}
as atividades têm vários caminhos; as crianças podem se envolver com eles até onde forem levadas pelos seus interesses e habilidades. Várias versões diferentes de alguns jogos e atividades são apresentadas para que as crianças possam ter uma ampla experiência com os conceitos relevantes. (ZASLAVSKY [15], 2009, p. 11).
\end{abstract}

Muniz [11] (2018) aponta que,

a ideia de jogo vem associada ao fato que uma atividade pode ser assumida como jogo para uma primeira pessoa, mas não o seja para uma segunda. Assim, a noção de jogo não está estritamente inserida na atividade em si, mas, em especial, no significado da mesma para os sujeitos que o realizam. (MUNIZ [11], 2018, p. 23).

"O jogo é concebido como um importante instrumento para favorecer as aprendizagens. Desta forma, o jogo se torna um instrumento pedagógico favorável no processo educativo" (MUNIZ [11], 2018 apud SARAIVA [14], 2015, p. 19).

De acordo D’Ambrosio ([8], 2019, p. 17-18), “a Etnomatemática é um programa de pesquisa que busca entender o saber/fazer matemático ao longo da história da humanidade, contextualizado em grupos diferentes, comunidades, povos e nações". Sabendo que 
jogos e brincadeiras estão intrinsicamente ligado ao mundo da criança, isso levou-nos a escolher o tema acima mencionado.

Ao falar da Etnomatemática como um programa de pesquisa em educação, o mesmo autor aponta que "ao insistir na denominação Programa Etnomatemática, procuro evidenciar que não se trata de propor outra epistemologia, mas sim de entender a aventura da espécie humana na busca de conhecimento e na adoção de comportamentos". (D’AMBROSIO, [8], 2019, p. 18).

O mesmo autor diz que é uma matemática praticada por grupos, ou seja, pessoas urbanas e rurais, assim como trabalhadores, classes profissionais, seres de certa faixa etária (crianças), grupos que se identificam por objetivos e tradições comuns aos grupos.

A Etnomatemática é uma das práticas que privilegia a concepção cultural. "Nessas concepções, a Matemática é sempre entendida como ciência e desvinculada de quem a produz ou para quem ela é produzida e de sua função na sociedade". (BANDEIRA, [7], 2016, p. 60).

Vários estudos sobre a Etnomatemática mostram que é uma matemática que procura questionar a

\begin{abstract}
universalidade da Matemática ensinada nas escolas, sem relação com o contexto social, cultural e político, procurando então dar visibilidade à matemática dos diferentes grupos socioculturais, especialmente daqueles que são subordinados do ponto de vista socioeconômico. (BANDEIRA, [7], 2016, p. 64).
\end{abstract}

Pesquisas sobre a Etnomatemática do cotidiano mostram uma matemática não apreendida nas escolas, mas no ambiente familiar ou na comunidade. No entanto, os profissionais desta sociedade praticam a sua própria Etnomatemática.

\title{
3 Caminhos metodológicos
}

Para atingir o principal objetivo da pesquisa que é - apresentar os primeiros resultados da investigação que teve como objetivo levantar/compreender a concepção de futuros professores de uma escola de magistérios primário em Chitato/Angola, acerca dos jogos e brincadeiras angolanos, como ferramenta didática no processo de ensino e de aprendizagem em matemática - percorreu-se vários caminhos, buscando aprofundar a análise e a compreensão sobre como essa temática se apresenta no contexto das investigações já existentes. Cabe ressaltar que neste artigo, serão apresentados resultados parciais, considerando dois jogos levantados.

Entre os caminhos percorridos, está a busca de referenciais na plataforma TÍDIA, utilizada como ferramenta tecnológica no curso de mestrado. Buscou-se por trabalhos acadêmicos junto à biblioteca digital de teses e dissertações da faculdade de Educação da 
Universidade de São Paulo - FEUSP. A escolha dessas fontes justifica-se pelo fato de possibilitarem a obtenção de algumas dissertações, artigos e teses defendidas, por possuírem informações sobre o tema e aportes teóricos que poderiam auxiliar na sustentação da dissertação. Para busca de teses e dissertações relacionadas com o tema de pesquisa, foram utilizadas algumas palavras-chave, tais como: Brincadeiras, Jogos e Etnomatemática.

A vida de um pesquisador pauta-se em percorrer trajetórias, traçar caminhos pelos quais vai passar, claro, dentro de uma área do conhecimento, e utilizar algumas referências para o problema ou objetivo de estudo. Esse movimento foi conduzido pela aplicação de um questionário aos futuros professores, 41 estudantes do $4^{\circ}$ ano de uma escola de magistério em Chitato/Angola.

O questionário é uma das formas mais usada para coletar dados, pois possibilita aferir, medir com mais exatidão o que se pretende. Ele é aplicado aos indivíduos previamente preparados e selecionados, e "pode ser aplicado simultaneamente a um maior número de indivíduos" (GOODE; HATT, [10], 1977, p. 227). Para este caso, a utilização do questionário permitiu obter informações, por meio de perguntas escritas, a respeito do tema em estudo.

Quivy e Campenhoudt ([13], 2003) consideram que o questionário

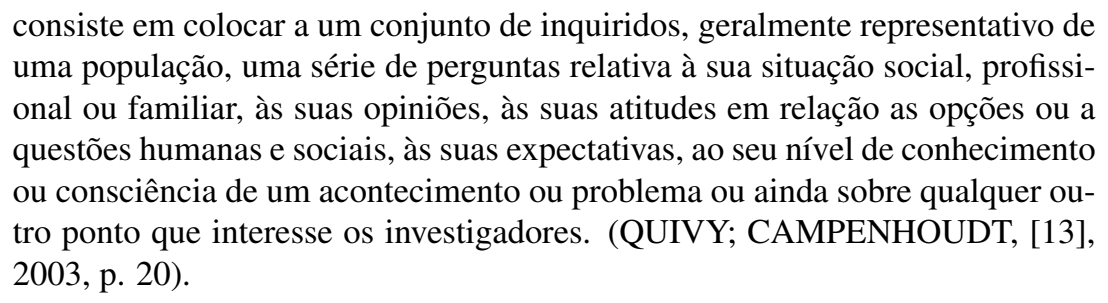

O questionário foi aplicado aos futuros professores, estudantes do $4^{\circ}$ ano de uma escola de magistério em Chitato/Angola e foi composto por questões fechadas e abertas, buscando levantar dados com o tema e objetivo da pesquisa, no sentido de obter informações escritas, assim como conhecer as ideias dos estudantes acerca dos jogos e brincadeiras angolanos no ensino de matemática.

$\mathrm{O}$ instrumento metodológico questionário foi utilizado para atender à seguinte pergunta da investigação: O que pensam os futuros professores de uma escola de magistério primário em Chitato/Angola acerca de Jogos e Brincadeiras angolanas no processo de ensino-aprendizagem da matemática? Neste artigo serão apresentados os primeiros resultados referentes a dois jogos.

O questionário consistiu de duas partes. A primeira com dados pessoais, para que se identificasse dentre alguns dados específicos, também a região de procedência dos futuros professores. Tal fato auxiliaria na identificação de jogos e brincadeiras culturais angolanas que poderiam ter variações de regras ou mesmo nomes diferentes em cada 
cultura. A segunda parte do questionário buscava levantar os jogos culturais angolanos que, na perspectiva dos futuros professores, teriam potencialidades didáticas para o ensino de matemática. Nesse sentido, elaborou-se as seguintes perguntas: - Quais são os jogos e as brincadeiras que são praticadas na sua região? - Nos jogos/brincadeiras que você conhece, quais você poderia utilizar na sala de aula como professor(a) de matemática no ensino primário? - Como você explicaria esses jogos/brincadeiras na sua sala de aula de matemática? Essas vertentes foram levantadas a partir do processo de leitura, releitura e transcrição dos dados da primeira pergunta.

Os elementos relacionados aos jogos e brincadeiras angolanas destacados que tiveram maior número de frequência foram: "o jogo da macaca", "brincadeira de garrafinha" e "jogo de Pedrinha".

Neste artigo serão evidenciados dois jogos apontados e duas vertentes: o resgate de valores culturais e o processo de contagem.

\section{Conhecendo o contexto}

Sabendo que o subsistema de ensino primário é uma área do ensino que se deve investigar ainda mais, para que isso aconteça, precisa-se de profissionais com melhor formação. Para tal, as escolas dos Magistérios Primários têm a responsabilidade de lançar para o mercado de emprego os melhores profissionais, e estes devem dar respostas à demanda que esse subsistema de ensino necessita. O subsistema de ensino primário é a base e alicerce do ensino geral, pois, se ela estiver mal alicerçada, então os resultados não serão satisfatórios. Com isso, o futuro profissional deve estar preparado para trabalhar com os alunos desse subsistema, conforme artigo 29 da Lei $n^{\circ}$. 17/16, de 7 de outubro, da Lei de Bases de Sistema de Educação e Ensino (Angola, [4], 2016), que em seus objetivos específicos traz:

a) Desenvolver a capacidade de aprendizagem, tendo como meios básicos o domínio da leitura, da escrita e do cálculo;

c) Aperfeiçoar hábitos, habilidades, capacidades e atitudes tendente à socialização;

e) Estimular o desenvolvimento de capacidade, habilidades e valores patrióticos, laborais, artísticos, cívicos, culturais, morais, éticos, estéticos e físicos. (LEI No. 17/2016, [4], p. 3997).

Com a finalidade que se propõe, pretende-se, com esta formação, que os futuros professores de matemática se preparem profissionalmente para a docência no Ensino Primário, de modo que no fim da sua formação tenham alcançado o seguinte perfil: 


\section{A nível do saber:}

a) conhecer-se e saber utilizar as suas capacidades e os seus recursos e ter consciência dos efeitos da sua atuação na sala de aula e na escola; b) conhecer a natureza fisiológica, psicológica e social da criança em idade pré-escolar e escolar; c) dominar os conteúdos programáticos e os manuais escolares, as normas, as orientações metodológicas e outros instrumentos relativos à educação e ensino nas instituições escolares; d) compreender os fatores de natureza legal, institucional e organizacional que contextualizam as práticas educativas na escola. e) conhecer as problemáticas mais relevantes do mundo em que vivemos, cada vez mais complexos e em rápida mudança;

2. A nível do saber/fazer:

f) definir objetivos específicos com base nos objetivos dos programas, das condições das instituições de ensino e do meio ambiente em que estão inseridos; g) identificar a criança com necessidades educativas especiais e proporcionar-lhe o encaminhamento adequado aos cuidados específicos de que carece; h) trabalhar em colaboração com os colegas da mesma classe; i) preparar as crianças para um enquadramento auspicioso no ensino subsequente e para uma opção vocacional consciente e compatível com inserção social harmoniosa na comunidade; j) desenvolver práticas de trabalho baseadas nas experiências de ensino e nas teorias de educação e ensino tendentes a formar cidadãos conscientes e participativos k) criar condições para uma aprendizagem:

- Globalizada, adotando métodos, meios de ensino e formas de organização para que as crianças vejam a realidade como um todo, particularmente nas seis primeiras classes e na classe de iniciação.

- Que promova o desenvolvimento integral e harmonioso da criança.

- Que propicie a integração e colaboração entre alunos e estes com o professor.

- Que decorra de uma gestão flexível e articulada dos programas, de modo que a generalidade dos alunos tenha sucesso nos conteúdos essenciais.

3. A nível do saber ser:

1) distinguir-se pelo elevado sentido de idoneidade moral e cívica, competência profissional, sabendo transmiti-lo aos seus educandos; m) estar motivado para uma aprendizagem permanente.

4. A nível do saber/conviver:

Ao trabalhar-se os três níveis anteriores, está-se a trabalhar também este nível, pois o mesmo é a convergência dos três níveis anteriores. (ANGOLA, [6], 2019, p. 18).

Com o perfil que os futuros professores devem possuir, é importante frisar que a escola em que o projeto foi desenvolvido está localizada no município do Chitato/Angola, por isso a razão de fazer uma abordagem do país como sendo uma República soberana e independente, que baseada na dignidade da pessoa humana e na vontade do povo angolano, tem como objetivo fundamental a construção de uma sociedade livre, justa, democrática, solidária, de paz, igualdade e progresso social. 
Diante desta realidade, tendo em conta a divisão político-administrativa do país, o artigo $8^{\circ}$ da Constituição da República de Angola ([1], 2010) define a estruturação das Províncias de acordo com a lei de alteração da divisão Político-Administrativa da Província da Lunda-Norte, que trata sobre os limites do município do Chitato, desanexa a Comuna do Lóvua e eleva-a à categoria de Município. A mesma legislação revoga o $n^{\circ}$. 2 do artigo $1 .^{\circ}$ do Decreto $n^{\circ} .84 / 78$, de 4 de julho. (Lei ${ }^{\circ} .5 / 15$, [2]).

Dentro dessas perspectivas, a Província tem uma área de aproximadamente $103.760 \mathrm{~km}^{2}$, com 10 municípios, 25 comunas, 122 bairros em áreas urbanas e 985 aldeias em áreas rurais. A seguir, a figura 1 traz os nomes dos municípios e línguas faladas na Província:

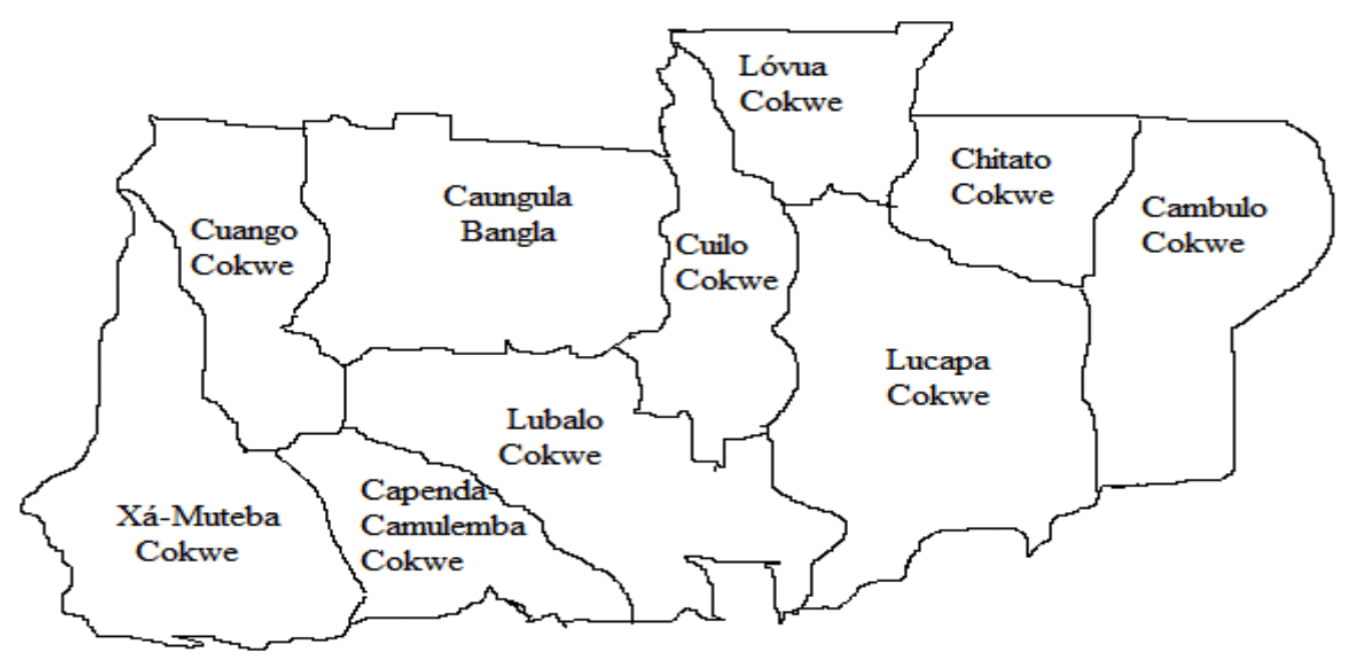

Figura 1: Mapa da Província da Lunda-Norte.

Fonte: Elaborado pelo autor.

Em função das informações contidas no mapa da Figura 1 acima, observa-se que é uma Província plurilíngue, onde a língua mais falada é Cokwe. Nessa perspectiva, é preciso frisar que o foco está no município do Chitato, pois é onde se encontra localizada a escola em estudo.

Entretanto, aborda-se sua instalação na Província da Lunda-Norte. O Decreto Executivo Conjunto $n^{\circ}$. 335/15 [5], dos Ministérios da Administração do Território e da Educação, estabelece a criação de uma Escola do II Ciclo do Ensino Secundário, do Magistério Primário em Chitato, com 19 salas de aulas, 57 turmas, 3 turnos e aprova o quadro de pessoal da escola. 


\section{$5 \quad$ Em busca de caminhos...}

Partindo do princípio de que os jogos podem ser considerados como atividades por meio das quais as crianças aprendem a apreciam a história e a cultura da sociedade em que estão inseridas, a partir da leitura, releitura análise das respostas relacionadas a pergunta de quais são os jogos que pertecem à região dos futuros professores e suas potencialidades didáticas, chegou-se a algumas vertentes tais como: o resgate de valores culturais e o processo de contagem e reconhecimento de formas geométricas.

A vertente "resgate de valores culturais" encontra-se nos dois jogos que serão apresentados a seguir, pois valoriza os saberes do cotidiano de cada região, evidenciando a dimensão se saberes do cotidiano presente no Programa Etnomatemática.

Já as vertentes "processo de contagem" e "reconhecimento de formas geométricas", são evidenciadas nas respostas dos futuros professores, acerca da potencialidade didática dos jogos, tal como pode-se constatar a seguir:

\section{- O jogo da Macaca}

A figura 2, a seguir, representa o jogo da macaca, conforme os angolanos o designam. Mas o objetivo dessa pesquisa é aproveitar no máximo o lado positivo do jogo, assim como sua implementação como ferramenta didática. Normalmente, é jogado pelas crianças, e acredita-se que tenha sido inventado pelos romanos, pois algumas gravuras mostravam as crianças brincando, nas ruas, nas aldeias, nos bairros, comunas e municípios.

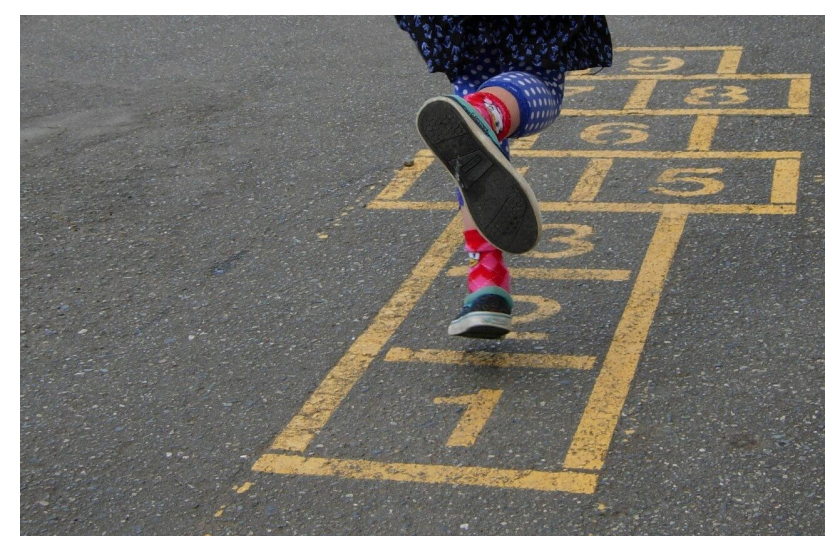

Figura 2: Criança jogando macaca.

Fonte: Pedagogia ao pé da letra [12]

O jogo consiste em pular sobre o desenho numerado (quadrado ou retângulo) de 1 a 9 , no caso seja no asfalto ou no chão bruto, com linhas caso seja na areia. Há várias versões 
do mesmo, mas adotou-se o figurino constante na Figura 2. Na verdade, as crianças têm usado como uma simples brincadeira, no entanto, há muitas coisas que podem ser exploradas em termos didáticos, na disciplina de matemática. Pode ser jogado por duas ou mais pessoas, mas no sentido de ser ainda mais atrativo, melhor que seja por três ou quatro crianças.

As Regras do Jogo começam da seguinte forma: escolhe-se na sorte quem vai ser o primeiro a jogar. Cada jogador joga uma tampinha, pedrinha (malha), inicialmente na casa número 1, devendo acertá-la em seus limites. Em seguida, o jogador pula em um pé só, nas casas isoladas, e com os dois pés, nas casas duplas, evitando a que contém a malha.

Chegando ao topo, no espaço oval, chamado céu, a criança pisa, com os dois pés, e retorna pulando da mesma forma até as casas 2, de onde o jogador precisa apanhar a pedrinha/malha no chão, sem perder o equilíbrio, e pular de volta ao ponto de partida; não cometendo erros, joga a pedrinha na casa 2 e sucessivas, repetindo todo processo.

Perde a vez quem pisar nas linhas do jogo, pisar na casa onde está a pedrinha, não acertar a pedrinha na casa onde ela deve cair, não conseguir (ou esquecer) de pegar a malha de volta. Ganha quem terminar de pular todas as casas primeiro.

A partir das respostas dos futuros professores, constatou-se que para o ato de jogar/brincar é tão importante, que a partir do momento em que vão jogando a malha nos quadrados ou retângulos numerados, eles estão desenvolvendo as primeiras aprendizagens relacionadas com a numeracia/numeração, assim como a contagem dos números. Também pode-se dizer que quando as crianças vão pulando em cada espaço numerado, o professor pode aproveitar e ensinar noções de geometria do plano. Para classes iniciais, pode-se ensinar as primeiras aprendizagens relacionadas aos números e às operações (contagem dos números) e geometria (noção de figuras e ângulos). Nesse jogo identificase as três vertentes: resgate de valores culturais, o processo de contagem e o reconhecimento de formas geométricas.

\section{- O jogo de pedrinhas}

O jogo de pedrinhas que pode ser jogado por duas ou mais pessoas. Para que se torne mais atraente e interessante, deve-se limitar o número de pessoas, que não pode ultrapassar quatro. A fim de que se jogue, é necessário: ter uma quantidade de pedras, que não se define quantas devem ser, mas dentre elas há uma que é diferente de todas, em termos de cor e tamanho, chamada de "mãe"; cavar um buraco com certo tamanho, ou seja, com um volume; e para além das quantidades de pedras que estarão no buraco, os jogadores devem ter em sua posse uma pedra que lhe possibilitará jogar, conforme Figura 3. 


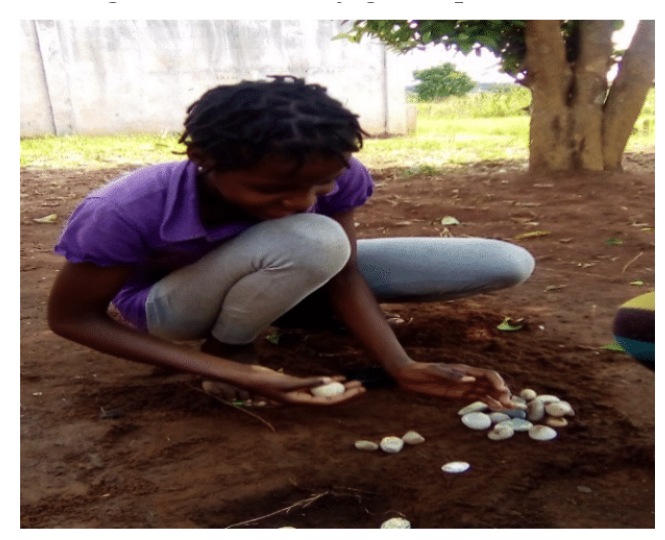

Figura 3: Criança jogando pedrinhas.

Fonte: Foto tirada pelo segundo autor.

As regras de jogo são: para que o jogo comece, um dos dois jogadores que for rápido a pedir, este será o primeiro a começar a jogar. Começado o jogo, o primeiro a jogar vai retirando uma quantidade de pedras do buraco, mas essa quantidade não é definida; depois, devolve-as ao mesmo buraco, ficando com uma pedra em sua posse, das que saíram do buraco, e assim sucessivamente, até que todas as pedras acabem do buraco, mas a "mãe" não pode ser retirada do buraco.

No caso, o primeiro jogador a perder, dá lugar ao seu adversário, e assim vão jogando até que termine o jogo. Retiradas todas as pedras do buraco, a única que fica é a "mãe". Entre os dois jogadores, o primeiro que retirar todas as pedras do buraco faz com que o seu adversário comece a colocar as pedras que ele possui no buraco, até que não fique com nenhuma, e quando isso acontece, o que fica em posse de todas as pedras retira a "mãe" do buraco, e terminado isso, é considerado vencedor.

Terminado o primeiro jogo, vão jogando pela segunda vez, e o vencedor, quando vai retirando as pedras do buraco, se no primeiro jogo, ao retirar as pedras do buraco, devolvia todas e ficava com uma, no segundo, devolve todas ao buraco e vai ficando com duas pedras em cada etapa do jogo. Isso vai acontecendo até terminar o jogo.

Ao se analisar as respostas dos futuros professores acerca desse jogo, pode-se dizer que para as crianças, jogar é uma diversão, mas como pretende-se levantar/compreender as possibilidades pedagógicas desse jogo, então ele pode ser aproveitado como ferramenta didática na aprendizagem da matemática, no que tange à contagem dos números, aplicação das regularidades, noção de números pares e ímpares, assim como adição e subtração dos números naturais. Desse modo, esse jogo evidencia as vertentes resgate de valores culturais e o processo de contagem.

A pesquisa ainda mostrou, a partir do depoimento dos futuros professores, que, aproveitando e explorando a cultura da criança, tendo em conta o que ela deve saber/fazer 
dentro do processo de ensino-aprendizagem da matemática, será possível compreender e implementar as possibilidades pedagógicas acerca de jogos e brincadeiras angolanas que fazem parte do cotidiano em sua própria cultura.

\section{Considerações}

Sabendo que toda pesquisa tem um propósito, um objetivo que leva a escrever e tendo já conhecimento de que em Angola pouco se fala, ou quase nada se fala, acerca da Etnomatemática, resultou em explorar profundamente os aspetos culturais, o que tem sido um pouco complicado, porque às vezes queremos que os inqueridos respondam ou façam segundo o ponto de vista do pesquisador, mas após a aplicação do questionário e a análise dos discurso dos futuros professores.

É nesse sentido que vai o pensar do pesquisador, realçando que com a introdução, a inclusão dos jogos e brincadeiras no sistema de ensino de Angola, numa perspectiva Etnomatemática, contribuiria no reaparecimento dos aspetos culturais que desde muito tempo vão desaparecendo nos municípios, comunas, bairros, aldeias e, especificamente, nas salas de aulas. Daí a importância de realizar a pesquisa que poderá dar alguma contribuição ao Ministério da Educação.

Os jogos angolanos apresentou possibilidades didáticas para o ensino de matemática, considerando o ambiente natural, social, cultural e imaginário de explicar, aprender, de conhecer, lidar com modos, estilos, artes e técnicas (Etnomatemática) de uma determinada sociedade.

\section{Referências}

[1] ANGOLA. Constituição da República de Angola, 2010.

[2] ANGOLA. Lei $\mathbf{N}^{0} \mathbf{5}$, de 6 de maio de 2015.

[3] ANGOLA. Currículo de formação de professores do pré-escolar e do ensino primário reforma curricular. Ministério da Educação, 2013.

[4] ANGOLA. Lei No. 17/2016, de 7 de outubro. Lei de Bases do Sistema de Educação - Diário Da República. Assembleia Nacional, $I^{\mathrm{a}}$ Série, $\mathrm{n}^{\circ}$. 65. Luanda: Imprensa Nacional, 2016.

[5] ANGOLA. Ministérios da Administração do Território e da Educação. Decreto $\mathrm{n}^{\circ}$ $335 / 15$, de 22 de abril de 2015. 
[6] ANGOlA. Plano Curricular do Ensino Secundário Pedagógico. Ministério da Educação. 1.ed. Editora Moderna, 2019.

[7] BANDEIRA, F. de S. Reflexões e ações pedagógicas em matemática do ensino fundamental. Edufrn Editora, 2016.

[8] D’AMBROSIO, U. Etnomatemática: Elo entre as tradições e a modernidade. Editora autêntica: Belo Horizonte, 2019.

[9] DE OLIVEIRA, C. C. As Dimensões da Etnomatemática na Construção do Conceito de Espacialidade: Um Estudo para a Primeira Série do Ciclo I. Revista da Educação, 2006.

[10] GOODE, Willian J.; HATT, Paul K. Métodos em pesquisa social. 6. ed. São Paulo: Companhia Editora Nacional, 1977.

[11] MUNIZ, Alberto, C. Brincar e Jogar "enlaces teóricos e metodológicos no campo de educação matemática”. 2. ed. Belo Horizonte: Autêntica, 2018.

[12] Jogos, brincadeiras antigas e cantigas de roda. Pedagogia ao pé da letra. Disponível em: https://pedagogiaaopedaletra.com/ jogos-brincadeiras-antigas-e-cantigas-de-roda/, Acesso em: 22 out. 2020.

[13] QUIVY, R.; CAMPENHOUDT, L. V. Manual de investigação em ciências sociais. Lisboa: Gradiva, 2003.

[14] SARAIVA, T. S. Quando brincar é aprender matemática: o jogo pedagógico e a construção de conhecimento matemático. 2015. Trabalho de conclusão de curso (Licenciatura em Pedagogia) ? Faculdade de Educação da Universidade de Brasília. Brasília, 2015.

[15] ZASLAVSKY, C. Mais jogos e atividades matemáticas do mundo inteiro: Diversão multicultural a partir dos 9 anos. Artmed: Porto Alegre, 2009.

口

Submetido em 06 nov. 2020

Aceito em 19 nov. 2020 